\title{
Examining Relationship between Palestine Stock Exchange and Amman Stock Exchange-Cointegration Approach
}

\author{
Abdul Razak Abdul Hadi ${ }^{1}$, Shadi Ali Hamad ${ }^{1}$, Mohamed Hisham Yahya ${ }^{2} \&$ Tahir Iqbal ${ }^{1}$ \\ ${ }^{1}$ University Kuala Lumpur Business School, Kuala Lumpur Malaysia, Malaysia \\ ${ }^{2}$ Accounting and Finance Department, University Putra Malaysia, Malaysia \\ Correspondence: Tahir Iqba, University Kuala Lumpur Business School, Kuala Lumpur Malaysia, Malaysia. \\ E-mail: tahir@unikl.edu.my
}

Received: December 11, 2012

Accepted: February 18, 2013

Online Published: March 26, 2013

doi:10.5539/ijbm.v8n7p133

URL: http://dx.doi.org/10.5539/ijbm.v8n7p133

\begin{abstract}
This paper aims at examining the probable equilibrium and dynamic relations between Palestine Stock Exchange (PEX) and Amman Stock Exchange (ASE). Within the framework of international trade theories, this study employs Engle-Granger Cointegration procedure (1987) as an estimation model involving monthly time series data from 1997 through 2011. The empirical results show that there is a significant equilibrium relationship between PEX and ASE, but fail to establish empirical evidence on dynamic relations between the two stock markets using Granger Causality tests. However, analysis of dynamic interactions during the post-sample period via Impulse-Response Functions and Variance Decomposition suggest that changes in ASE index do influence the performance of PEX.
\end{abstract}

Keywords: PEX, ASE, cointegration procedure, granger causality test, stock market index

\section{Introduction}

A myriad of studies examining relationship between two regional stock market performances are pursued by researchers and analysts. It is important to find out the potential theoretical link between the two regional stock markets, with focus on identifying the potential long-run and short run relationships between them. Different stock market set up and distinct regulatory frameworks may create an investment environment conducive for market participants, in particular investors and hedgers. As such, one needs to understand the characteristics of the individual markets and the level of their informational efficiency.

Palestine is a new born economy and expected to share many of its market attributes with the long established trade partners in the Arab region. Occupation of Palestine, a special demographic relationship between Palestine and Jordan population and the joint Hashemite rule from 1951 to 1967, are among the important factors that may lure investors from other countries to diversify their investments in the region (Palestinian National Authority, 2011).

The main obstacles to the economic growth of Palestine are land accessibility and weak financial system. Import and export restrictions by the Israeli government and high financing costs are also some of the prominent problems. With the absence of private investment, Palestinian national authority continues to rely heavily on foreign aid for its budgetary needs. Tax revenues have always been lower than anticipated and real GDP per capita was approximately USD 127 on a monthly basis. Similar to Lithuania, the growth prospect for Palestine remains uncertain so long as the two main issues discussed above remain unsolved. It is important to note that the wellbeing of any financial market is indeed a function of sound macroeconomic policies (Pilinkus, 2009).

The Jordanian and Palestinian stock exchanges have been losing their positive momentum since the last three years. Both stock markets have been sustaining huge drop in the trading value and volumes have been plummeting quite rapidly. Partly, the weak sentiment in both stock markets could be due to the slowing down of world economy plus the structural change in the political systems in the Arab region particularly in Egypt, Libya and Syria.

In terms of national income among all economies in the Middle East, Jordan is considered the smallest with problems in basic supplies such as water, heating oil, and foods. Other challenges that the current government is attempting to deal with are to reduce the unemployment rate, to check the budget deficit as well as to curtail inflationary spiral. The GDP in 2011 was $\$ 36.8$ billion, a marginal increase from 36.01 billion in 2010. The 
annual GDP growth rate was $2.5 \%$ in 2011 , slightly higher than $2.3 \%$ registered in 2010. Jordan economy relies on its service sector, which contributes $65 \%$ to the total value of GDP. In terms of manpower utilization, $77.4 \%$ of the Jordanian labor forces are involved in the service sector, while the remaining in the manufacturing industries. Jordanian public debt stood at $60.7 \%$ of its GDP in 2011, while inflation has been hovering between $5 \%$ and $6 \%$ over the last three years (World Bank, 2011).

Several standard trade theories can be appraised to explain the trade and market relations between Palestine and Jordan. Smith (1776) advocates that increase in trade can be achieved through improving the division of labor which in turn will enhance the level of productivity. Smith also emphasizes that having an open market and regional trade will give rise to capitalism and economic growth. The study of Smith was advanced by Ricardo (1817). Ricardo proposes that international trade should be based on relative efficiencies (producing at lower opportunity cost) involving the trading nations. For instance, two trading nations will gain from international trade if they have different relative costs for producing the same goods. The Heckscher-Ohlin Theory (1933) builds on Ricardo's Theory of Comparative Advantage and it suggests that the patterns of trade should be based on the factor endowments of the trading nations.

Heckscher (1919) and Ohlin (1933) support trade liberalization because such an approach will increase supply of cheaper raw materials and fixed capital goods. Increase in international trade activities among trading nations will stimulate faster export expansion which in turn leads to a stronger gross domestic product contribution. Baysan (1999) advocates that, trade liberalization contributes towards positive productivity growth. Therefore, the importance of trade liberalization between Palestine and Jordan in driving dynamic productivity gains and economic growth should not be overlooked.

Empirical evidence from earlier researchers indicates that the relationship between trade liberalization and income growth is rather well-built. Based on Hecksher-Ohlin Theory, a newly born country like Palestine is likely to benefit from international trade with respect to income growth and poverty reduction. Dollar (1992) discovers a positive co-relationship between a measure of per capita GPD growth and outward orientation after examining 95 developing countries. Wacziarg (1998) suggests, after investigating on 57 countries, that trade liberalization has a profound effect on growth of national income. Likewise, Frankel and Romer (1996) conclude, after having cross-country regressions, that trade has a robust effect on income. Having this empirical evidence, it is safe to say that open trade allows a developing county to grow faster which in turn lead to an effective and efficient allocation of resources (Ahmed and Sattar, 2004).

There have been a lot of studies on financial market integration and efficiencies involving countries in Middle East but only a few were ever made in the Palestinian case (Benjamin and Eduardo, 2002; Claude, 2006; Kamal, 2005; Richard, 2012). Murad and Haneen, (2010) suggest that it is worth studying the degree of market integration involving both financial markets in Palestine and Jordon. Said, Mahmoud and Hanim (2008) find that most Arab countries in the Middle East are now moving towards modernizing and harmonizing their financial systems, including their reporting standards. However, quite a number of these countries are still suffering from bureaucratic administration and weak legal system which prevent them from developing their financial markets to the fullest. Duffy and Murry (1994) explain that there has been initiative by many regulatory bodies over the last 10 years towards harmonization of different national accounting standards with the objective of improving the quality of reporting to investors.

Bank for International Settlements (2009) reports that global capital market has been growing rapidly over the last 10 years. Dicken (1992) associates this tremendous growth of global capital market with advances in information technology and government deregulation in many countries. As such, one cannot undermine the investment potential of volatile Arab region like Palestine. Domowitz, Glen and Madhavan (1997) postulate that investors must understand market segmentation across an economic region in order to benefit from diversification effect. They exemplify the situation during Asia Debt Crisis in 1997 in which both U.S and Europe markets are not affected by the financial fiasco in Asia. While most of the stock markets in Asian countries lost over 50 percent of their value, the S\&P 500 performed remarkably and enjoyed 20 percent increase in value. The implication is that through deep understanding of regional markets and current global trends, investors are able to deploy an effective diversification strategy for their portfolios no matter where they are.

The main motivation of this paper is to investigate the directional relationship between PEX and ASE, as well as to measure the relative strength of the relationship. Many empirical studies indicate that a strong regional economy helps sustaining economic prosperity of its member countries. As far as PEX is concerned, the Arab countries, particularly Jordan have been playing pivotal roles in building up Palestine capital markets. This 
paper is deemed important as it provides useful insights not only to local investors but also to those who are interested in venturing into Palestine stock exchange's potential. This study employs econometric time series analysis, Engle-Granger Cointegration approach (1987), to develop a predictive model on the two emerging stock markets. Hadi, Yahya and Shaari (2009) adopt the same approach in testing market integration involving commodities like crude oil, coal and natural gas. This study attempts to answer the following research questions in particular:

1) Does movement in ASE index over time affect the performance of PEX?

2) Is there any causality effect involving the two neighboring stock markets?

3) Is it theoretically true that ASE is the leading indicator in the tested model?

\section{Data and Methodology}

The study employs Vector Auto-Regressive Modeling (VAR) and Granger-Causality test as the main research tools in investigating the equilibrium and short-run relations between PEX and ASE. The co-movements of these two market indexes over time are demonstrated in Chart 1 below. PEX is proxied by Al-Quds Index while ASE is represented by Amman Stock Exchange Index. In revealing possible theoretical relations between the two market indexes, the procedure used by Lance and James (2006) is replicated. Figure 1 below summarizes the overall research framework.

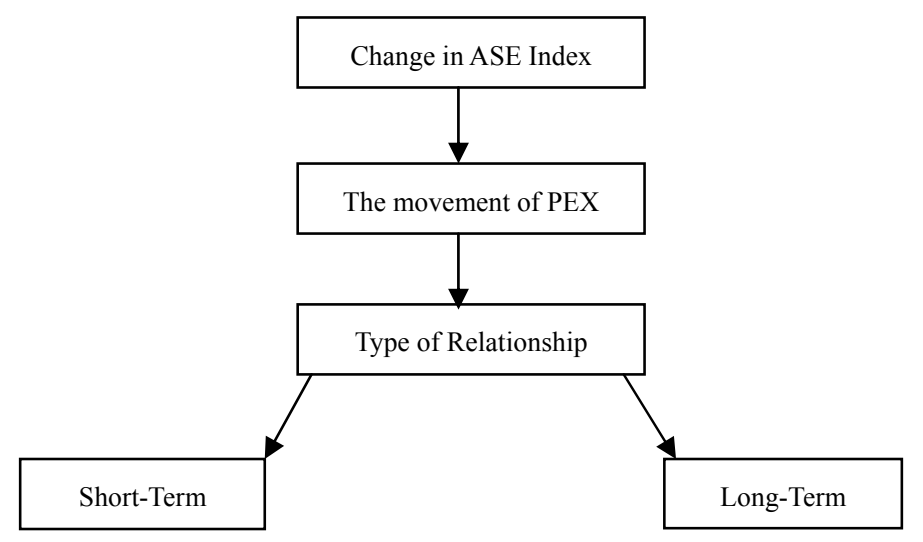

Figure 1. Research framework

The study begins with stationarity tests on the time series variables (via Augmented Dickey-Fuller Tests), followed by Engle-Granger Cointegration modeling. Ultimately, Granger causality test (within sample) is carried out to determine the presence of short-run relation between the tested variables.

The study considers monthly observations on the two market indexes. The observation period spans from July 1997 till April 2012 involving 176 data points. Engle-Granger Cointegration test (1992) is employed to examine the statistical relation between the PEX and ASE. This procedure is performed to explore any probable association between the two market indexes. Cointegration test is a statistical method developed by Granger and Weiss (1981) and later improvised by Granger (1986), Granger and Weiss (1983) and Engle and Granger (1987). Due to its dynamic functions, this statistical technique has received wide attention among researchers and has been used to test the validity of various theories and models. Cointegration is essentially an econometric technique for testing the correlation between non-stationary time series variables. Two time series variables are said to be cointegrated when a linear combination of the two is stationary, even though each variable is non-stationary on its own. Generally when $\mathrm{X}$ and $\mathrm{Y}$ variables are non-stationary, one would anticipate that a linear combination of the two variables would also be non-stationary. Interestingly, this perception has been proven otherwise by Engle and Granger (1987). Based on the arguments put up by Granger (1981) and Engle Granger (1987), components in vector $\mathrm{Y}_{\mathrm{t}}$ is cointegrated at $d, b$ degree if:

(i) All components of $Y_{t}$ is $I(d)$

(ii) There is a nonzero vector $\beta=\left(\beta_{1}, \beta_{2}, \ldots, \beta_{\mathrm{n}}\right)$ so that the linear combination of $\beta \mathrm{Y}_{\mathrm{t}}=\beta_{1} \mathrm{Y}_{1 \mathrm{t}}+\beta_{2} \mathrm{Y}_{2 \mathrm{t}}+\ldots+$ $\beta \mathrm{nY} \mathrm{nt}_{\mathrm{nt}}$ will be cointegrated at $(d-b)$ degree where $b>0$. The vector $\beta$ is the cointegration vector. 
In addressing problem of non-stationarity among data series, it is necessary to make use of first (or higher) differentiated data. However, it is important to note that this differencing technique may result in a loss of precious data points on long-run characteristics of the time-series data. Engle and Granger (1987) postulate that, if there is an equilibrium relationship between such variables, then the disequilibrium error should fluctuate about zero i.e. error terms should be stationary. As such, unit root test is important in determining the stationarity of time series data. Whether the tested variable has the tendency to return to its long term trend after a shock (i.e. it is stationary) or exhibits a random walk pattern (i.e. it has a unit root), this important question needs to be answered before any further analysis is warranted. Any presence of unit root would suggest a spurious regression relationship. This study uses the Augmented Dickey Fuller test in examining unit root problem and expressed as follows:

$$
\Delta Y_{t}=\lambda_{0}+\lambda_{1} T+\lambda_{2} Y_{t-1}+\Sigma \lambda_{i} \Delta Y_{t-i}+\varepsilon_{t}
$$

where $i=1,2,3 \ldots \mathrm{k}$.

The hypotheses being tested are:

$\mathrm{H}_{0}: \lambda_{2}=0$ (the data is not stationary, it contains unit root)

$\mathrm{H}_{1}: \lambda_{2}<0$ (data is stationary, it does not contain unit root)

The moment the tested data series are stationary at first difference (or higher), they are said to be cointegrated. Subsequent to that, the Vector Error Correction Model (VECM) technique can now be deployed. Vector Error Correction Model (VECM) is a restricted Vector Autoregressive (VAR) technique. VECM is a unique technique that restricts the long run behaviour of endogeneous variables to converge to its cointegrating relationship. On the top of that, it also allows for short run adjustments among the tested variables. The VECM model is formulated as follows:

$$
\Delta Y_{t}=\mu_{i}+\sum_{i=1}^{n} A_{i} \Delta Y_{t-i}+\sum_{i=1}^{n} \xi_{i} \Theta{ }_{t-i}+v_{t}
$$

Where:

$\mathrm{Y}_{\mathrm{t}}$ is in the form of $\mathrm{n} \times 1$ vector

$\mathrm{A}_{\mathrm{i}}$ and $\xi_{\mathrm{i}}$ are the estimated parameters

$\Delta$ is the difference operator

$\mathrm{v}_{\mathrm{t}}$ is the reactional vector that explains unanticipated movements in $Z_{\mathrm{t}}$ and $\Theta$ (error correction term)

The VECM technique makes it possible to separate short-term adjustment from long-term relationships. Refer the research flow shown in Figure 2 below. Regression analysis is based on Ordinary Least Square Method (OLS) and subjected to Classical Normal Linear Regression assumptions. In ensuring all statistical findings are valid, those fundamental assumptions must be observed. Hence, full diagnostic tests comprise of Augmented-Dickey Fuller unit root test, Moments of Specification Test/White test, Durbin-Watson test, Anderson-Darling test and Variance Inflation Technique are carried out. In investigating directional relationship between PEX and ASE, the study assumes only one causal direction: ASE affects PEX. It is a conventional wisdom that an established financial market will generally influence a newly set up stock exchange like Palestine Stock Exchange.

Specifically, the forecasting model underlying this study is expressed as follows:

$$
P E X_{t}=\beta 0+\beta 1 A S E_{t}+\varepsilon_{t}
$$

Where:

PEX $=$ Palestine Stock Exchange (proxied by Al-Quds Index).

ASE $=$ Amman Stock Exchange Index.

$\varepsilon_{\mathrm{t}}=$ Error Terms. 


\section{Cointegration Between PEX and ASE From July 1997 Through April 2012}

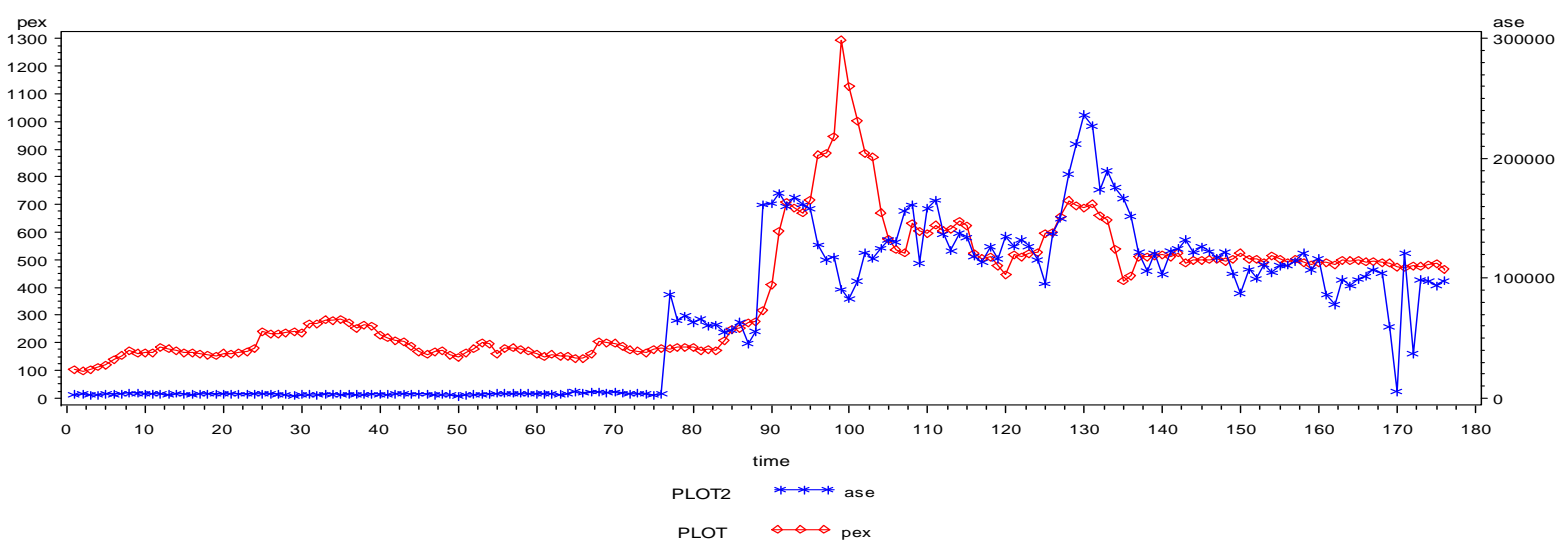

Figure 2. Movements PEX and ASE over sample period

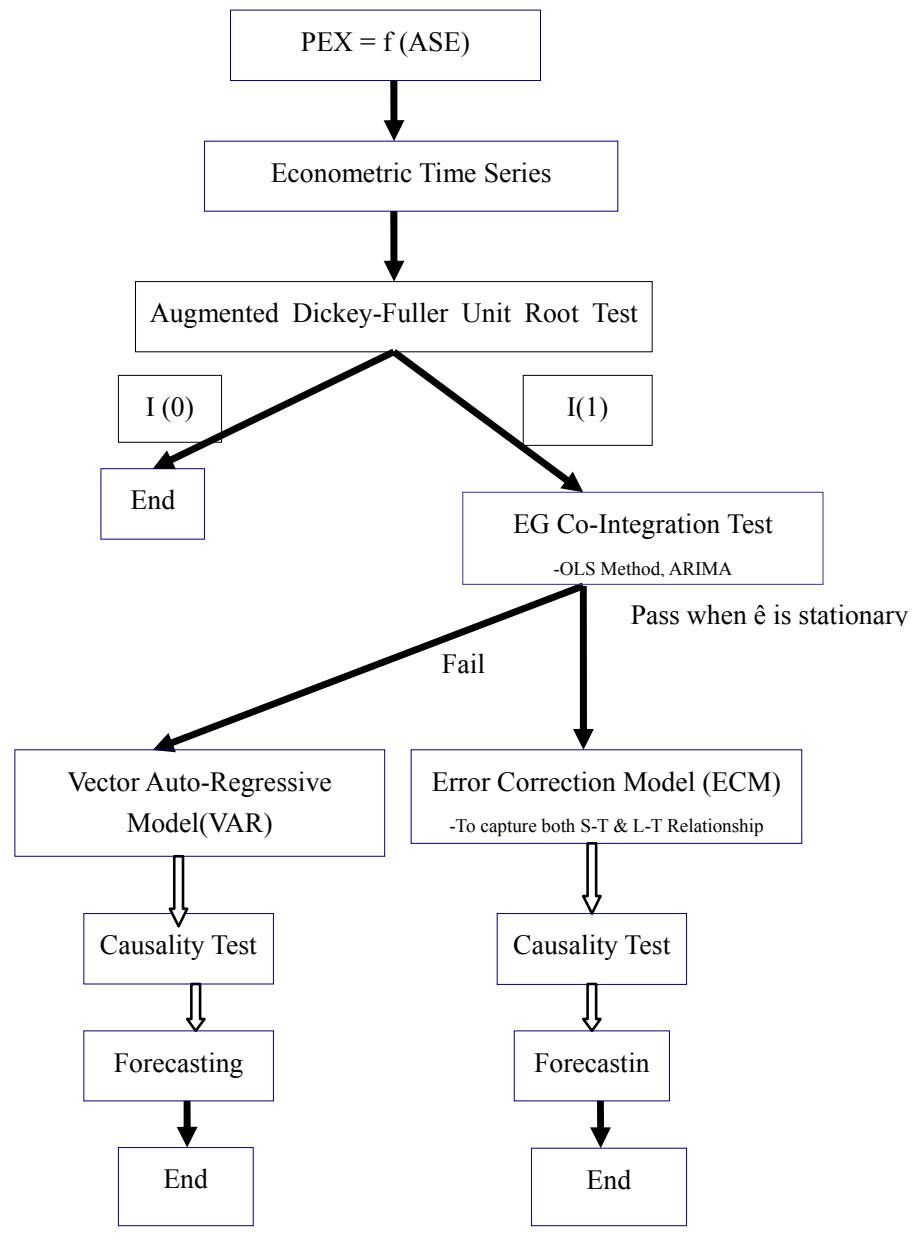

Figure 3. Research flow on effect of ASE upon PEX

\section{Empirical Findings}

To investigate the effect of changes in ASE index on PEX performance (proxied by Al-Quds index), some statistical tests in time-series econometric modeling must be carried out. In particular, the key statistical tests are Augmented Dickey-Fuller Unit Root Test (ADF) and Bi-variate Cointegration Tests (ECM). Table 1 and Table 
2 below provide the results from unit root tests on PEX and ASE at level respectively.

Hypothesis testing is performed to determine the significance level of the unit root test. Table 1 reports the P-values that indicate the level of significance. From the test statistics presented in Table 1 and Table 2, it is evident that both PEX and ASE are non-stationary at all lags. On contrary, the P-values from Table 3 and Table 4 indicate that the first-differenced PEX and ASE series are consistently stationary at all lags. The study finds that both PSE and ASE are integrated at first difference. As such, the preliminary requirements in Enger-Granger Cointegration procedure have now been fulfilled.

Table 1. Unit root test on PEX at level (via ADF)

$\mathrm{H}_{0}$ : Data series are non-stationary (unit root problem); $\mathrm{H}_{1}$ : Data series are stationary (no unit root problem)

\begin{tabular}{cccc}
\hline Type & Lags & p-value & Tau \\
\hline & 1 & 0.4486 & -0.62 \\
Zero & 2 & 0.4563 & -0.60 \\
Mean & 3 & 0.3824 & -0.77 \\
& 4 & 0.3611 & -0.82 \\
\hline & 5 & 0.4426 & -0.63 \\
\hline Single & 1 & 0.2864 & -2.00 \\
Mean & 2 & 0.3000 & -1.97 \\
& 3 & 0.2029 & -2.21 \\
\hline & 4 & 0.1759 & -2.29 \\
\hline & 5 & 0.2898 & -1.99 \\
\hline
\end{tabular}

Table 2. Unit root test on ASE at level (via ADF)

$\mathrm{H}_{0}$ : Data series are non-stationary (unit root problem); $\mathrm{H}_{1}$ : Data series are stationary (no unit root problem)

\begin{tabular}{cccc}
\hline Type & Lags & p-value & Tau \\
\hline & 1 & 0.3603 & -0.82 \\
ZERO & 2 & 0.3709 & -0.80 \\
MEAN & 3 & 0.3431 & -0.86 \\
& 4 & 0.3491 & -0.85 \\
\hline & 5 & 0.4065 & -0.71 \\
\hline SINGLE & 1 & 0.4204 & -1.72 \\
MEAN & 2 & 0.4283 & -1.70 \\
& 3 & 0.3890 & -1.78 \\
& 4 & 0.3945 & -1.77 \\
\hline & 5 & 0.4615 & -1.64 \\
\hline
\end{tabular}


Table 3. Unit root test on first-differenced PEX (via ADF)

$\mathrm{H}_{0}$ : Data series are non-stationary (unit root problem); $\mathrm{H}_{1}$ : Data series are stationary (no unit root problem)

\begin{tabular}{|c|c|c|c|}
\hline Type & Lags & p-value & Tau \\
\hline \multirow{5}{*}{$\begin{array}{l}\text { Zero } \\
\text { Mean }\end{array}$} & 1 & $<0.0001$ & -8.36 \\
\hline & 2 & $<0.0001$ & -6.11 \\
\hline & 3 & $<0.0001$ & -5.30 \\
\hline & 4 & $<0.0001$ & -5.70 \\
\hline & 5 & $<0.0001$ & -5.56 \\
\hline \multirow{5}{*}{$\begin{array}{l}\text { Single } \\
\text { Mean }\end{array}$} & 1 & $<0.0001$ & -8.36 \\
\hline & 2 & $<0.0001$ & -6.10 \\
\hline & 3 & $<0.0001$ & -5.30 \\
\hline & 4 & $<0.0001$ & -5.70 \\
\hline & 5 & $<0.0001$ & -5.56 \\
\hline \multirow{5}{*}{ Trend } & 1 & $<0.0001$ & -8.35 \\
\hline & 2 & $<0.0001$ & -6.10 \\
\hline & 3 & 0.0001 & -5.30 \\
\hline & 4 & $<0.0001$ & -5.70 \\
\hline & 5 & $<0.0001$ & -5.56 \\
\hline
\end{tabular}

Table 4. Unit root test on first-differenced ASE (via ADF)

$\mathrm{H}_{\mathrm{o}}$ : Data series are non-stationary (unit root problem); $\mathrm{H}_{1}$ : Data series are stationary (no unit root problem)

\begin{tabular}{cccc}
\hline Type & Lags & p-value & Tau \\
\hline & 1 & $<0.0001$ & -10.70 \\
Zero & 2 & $<0.0001$ & -7.85 \\
Mean & 3 & $<0.0001$ & -6.70 \\
& 4 & $<0.0001$ & -6.52 \\
\hline & 5 & $<0.0001$ & -6.28 \\
Single & 1 & $<0.0001$ & -10.69 \\
Mean & 2 & $<0.0001$ & -7.84 \\
& 3 & $<0.0001$ & -6.70 \\
& 4 & $<0.0001$ & -6.52 \\
& 5 & $<0.0001$ & -6.28 \\
\hline & 1 & $<0.0001$ & -10.66 \\
& 2 & $<0.0001$ & -7.83 \\
& 3 & $<0.0001$ & -6.69 \\
& 4 & $<0.0001$ & -6.52 \\
\hline
\end{tabular}

Once the preliminary requirements have been met, the study moves on to the next procedure. Now, long-run regression is performed on the PEX and ASE data series (based on the model specification). Table 5 presents the results from the regression analysis and shows that the null hypothesis is rejected. This suggests that there is a statistically significant positive relationship between PEX and ASE. Table 6 and Table 7 provide the descriptive statistics and the correlation matrix of the two market indexes respectively. It is interesting to point out that there is a strong correlation between PEX and ASE. In order for OLS estimation to be statistically valid, Engle-Granger (1987) suggests that the long-run residuals derived from the long-run regression (r) must be stationary. Hence, the unit root test (via ADF) on the long-run residuals is performed and results are reported in Table 8. As expected, the long-run residuals (r) are stationary at all lags. At this point, it is important to highlight two important implications. First, as the long-run residuals are proven stationary, the PEX and ASE are said to be co-integrated. Secondly, having said that PEX and ASE are co-integrated, the Vector Error Correction Model (VECM) can now be considered for further analysis. 
Table 5. Analysis of long-run regression ( $\mathrm{PEX}=$ dependent variable)

$\mathrm{H}_{0}$ : No Long-term relationship exists between PEX and ASE; $\mathrm{H}_{1}$ : Long-term relationship exists between PEX and ASE

\begin{tabular}{cccc}
\hline Variable & Parameter Estimate & Standard Error & t-Value \\
\hline Intercept & 189.8930 & 15.1936 & $12.50^{*}$ \\
ASE & +0.0028 & 0.0001 & $17.44 *$ \\
\hline
\end{tabular}

* Significant at 5\% level.

Table 6. Descriptive statistics

\begin{tabular}{cccccc}
\hline Variable & $\mathrm{N}$ & Mean & Std Dev & Minimum & Maximum \\
\hline PEX & 176 & 384.4873 & 227.4265 & 97.01 & 1295.08 \\
ASE & 176 & 68309.87 & 63998.09 & 1663.93 & 236586.33 \\
\hline
\end{tabular}

Table 7. Pearson correlation table $(\mathrm{n}=176)$

\begin{tabular}{ccc}
\hline & PEX & ASE \\
\hline PEX & 1.00000 & 0.7975 \\
& & $<0.0001$ \\
ASE & 0.7975 & 1.00000 \\
\hline
\end{tabular}

Table 8. Stationarity test for long-run residuals (r)

$\mathrm{H}_{0}$ : Residuals have a unit root (non-stationary); $\mathrm{H}_{1}$ : Residuals have no unit root (stationary)

\begin{tabular}{cccc}
\hline Type & Lags & p-value & Tau \\
\hline & 0 & $<0.0001$ & -3.97 \\
Zero & 1 & 0.0003 & -3.72 \\
Mean & 2 & 0.0002 & -3.76 \\
& 3 & 0.0001 & -3.94 \\
& 4 & $<0.0001$ & -4.31 \\
\hline
\end{tabular}

\subsection{Vector Error Correction Model (VECM)}

The PEX and ASE variables in the model are estimated using Vector Error Correction technique. This forecasting technique investigates long term and short term responses involving the two tested variables. Based on the Akaike results (AIC), the optimum lag-length for the tested model lies at lag 2 (VECM technique prefers lower AIC value). Table 9 summarizes all relevant test results.

Table 9. Vector error correction model at lag 2 (dependent variable: dPEX)

\begin{tabular}{ccccc}
\hline Variables & Parameter & Standard Error & t-Value & P-Value \\
\hline Intercept & 1.5045 & 3.5662 & 0.42 & 0.6736 \\
Ldpex & 0.2350 & 0.0746 & 3.15 & 0.0019 \\
12dpex & 0.0475 & 0.0753 & 0.63 & 0.5291 \\
$l r$ & -0.1053 & 0.0283 & $-3.72^{*}$ & $0.0003^{*}$ \\
Ldase & 0.0001 & 0.0001 & 0.86 & 0.3937 \\
12dase & -0.00001 & 0.0001 & -0.86 & 0.9541
\end{tabular}

Notes: dpex is first difference in PEX, ldpex is lag 1 of first difference in PEX; 1r is lag 1 residual and ldase is lag 1 of first difference in ASE. 
The $l r$ is a lag 1 residual derived from VECM (2). It is the key component in VECM that supports long-term or equilibrium relationship between PEX and ASE. From $l r$ 's p-value reported in Table 9, there is a statistically significant equilibrium relation between the two stock market indexes. Given $l r$ 's parameter value of 0.1053 , this figure implies that there is approximately $10.53 \%$ speed of adjustment towards equilibrium made by PEX in the system. The reaction of PEX in adjusting into the system is considered relatively fast and it could be attributed to the market integration between the two stock markets as postulated by many market analysts. Theoretically, higher speed of adjustment is preferred because a statistically reliable endogenous variable should reflect high speed in its equilibrium adjustment.

Table 10. Granger causality test (short-run dynamics)

\begin{tabular}{cccc}
\hline Source & DF & F-Value & Pr $>$ F \\
\hline Numerator & 2 & 0.44 & 0.6473 \\
Denominator & 167 & & \\
\hline
\end{tabular}

Note that the positive parameter value of ASE $(+0.0028)$ in Table 5 signifies a statistically significant positive relationship between PEX and ASE. This implies that both PEX and ASE are positively correlated. Now that the presence of long-term relationship between PEX and ASE are significant, there is also a possible short-term relation between them. As such, Granger Causality test is conducted and its test results are reported in Table 10 above. The F-value reported indicates that the alternative hypothesis is rejected. This suggests that there is an absence of short-term relationship between PEX and ASE. In ensuring that the OLS assumptions are put in check, diagnostic tests are carried out on the theoretical model.

\subsection{LM Tests for ARCH Disturbances}

To determine as to whether the error terms have constant variance, LM ARCH test is performed. The test results are shown in Table 11 below. From the test statistic, the study fails to reject $\mathrm{H}_{0}$ at $5 \%$ significance level at order 11. This indicates that the residuals are homoscedastic or operating at constant variance.

Table 11. LM tests for ARCH disturbances

$\mathrm{H}_{0}$ : Homoscedastic (Constant variance in $\varepsilon_{\mathrm{t}}$ ); $\mathrm{H}_{1}$ : Heteroscedastic (Inconstant variance in $\varepsilon t$ )

\begin{tabular}{ccc}
\hline Order & LM & Pr $>$ LM \\
\hline 1 & 6.7415 & 0.0094 \\
2 & 6.9977 & 0.0302 \\
3 & 11.4176 & 0.0097 \\
4 & 11.4440 & 0.0220 \\
5 & 15.9018 & 0.0071 \\
6 & 17.0511 & 0.0091 \\
7 & 17.1461 & 0.0165 \\
8 & 18.6582 & 0.0168 \\
9 & 18.7313 & 0.0276 \\
10 & 18.8327 & 0.0424 \\
11 & 19.1195 & 0.0590 \\
\hline
\end{tabular}

\subsection{Tests for Normality}

Normality test on error terms distribution is necessary before any statistical inference can be derived. The test statistics for normality are based on the empirical distribution function involving Kolmogorov-Smirnov, Cramer-von Mises, and Anderson-Darling statistics. 
Table 12. Normality test (variable: short-run residuals)

\begin{tabular}{cccc}
\hline Test & & Statistic & P-Value \\
\hline Shapiro-Wilk & $\mathrm{W}$ & 0.6781 & $<0.0001$ \\
Kolmogorov-Smirnov & $\mathrm{D}$ & 0.2020 & $<0.0100$ \\
Cramer-von Mises & $\mathrm{W}-\mathrm{Sq}$ & 2.5959 & $<0.0050$ \\
Anderson-Darling & $\mathrm{A}-\mathrm{Sq}$ & 13.7555 & $<0.0050$ \\
\hline
\end{tabular}

The null hypothesis states the short-term residuals are normally distributed.

Table 12 summarizes the test results and as a whole the error terms from ECM (2) are not normally distributed using all the four test statistics (see p-value). These findings may have been seen as flaw but this shortcoming is still manageable considering the study's preliminary nature.

\subsection{Autocorrelation Test}

Autocorrelation test is conducted to examine any existence of serial correlation among the short-term residuals. Diagnostically, it is important to ensure that all residuals are independent of one another. Table 13 shows Durbin-Watson test results and there is an absence of autocorrelation among the residuals.

Table 13. Autocorrelation test (via ljung-box test) (dependent variable: dPEX)

\begin{tabular}{cc}
\hline To Lag & Pr $>$ ChiSq \\
\hline 6 & 0.0591 \\
12 & 0.1854 \\
18 & 0.1859 \\
\hline
\end{tabular}

No serial correlation or autocorrelation exists.

Cusum Test For Structural Break (r3)

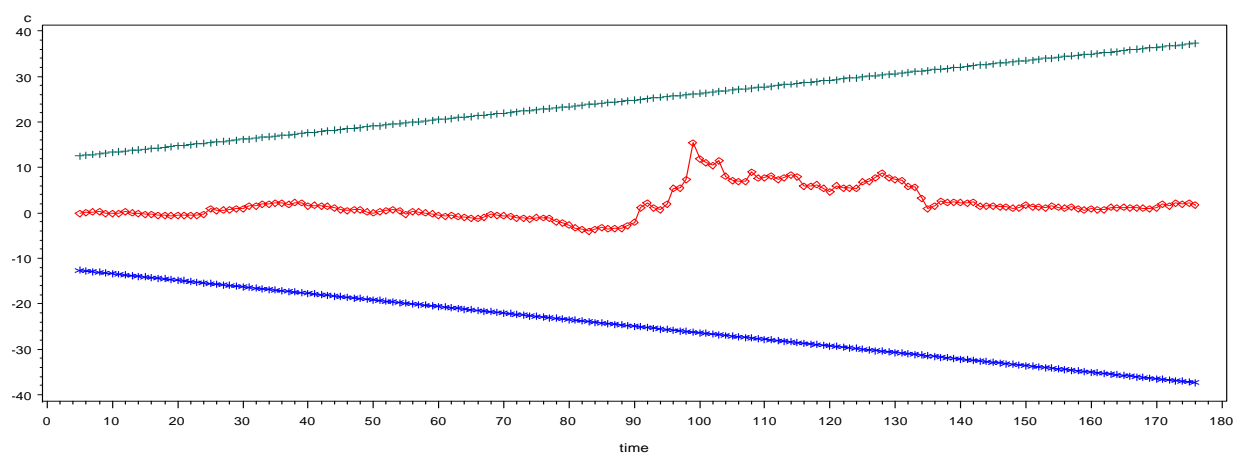

Figure 4. CUSUM test (on short-run residuals of the model)

CUSUM analysis (or cumulative sum of residual test) is one of the important tools in econometric modeling. This technique is deployed to address diagnostic problems associated with parameter instability. Looking at Chart 2 above, the CUSUM analysis indicates presence of parameter stability (short-run and long-run parameters) since the short-run residuals lie within the lower and upper boundaries. As a whole, the predictive model developed from this study can be considered credible since the tested model does not suffer from any major diagnostic shortcoming. 
Table 14. Simple impulse response by variable

\begin{tabular}{|c|c|c|c|}
\hline Variable ResponselImpulse & Lag & PEX & ASE \\
\hline \multirow{20}{*}{ PEX } & 1 & 1.14128 & 0.00048 \\
\hline & 2 & 1.04910 & 0.00073 \\
\hline & 3 & 0.92539 & 0.00096 \\
\hline & 4 & 0.81123 & 0.00113 \\
\hline & 5 & 0.71622 & 0.00127 \\
\hline & 6 & 0.63915 & 0.00138 \\
\hline & 7 & 0.57729 & 0.00147 \\
\hline & 8 & 0.52777 & 0.00154 \\
\hline & 9 & 0.48819 & 0.00160 \\
\hline & 10 & 0.45655 & 0.00164 \\
\hline & 11 & 0.43128 & 0.00168 \\
\hline & 12 & 0.41108 & 0.00171 \\
\hline & 13 & 0.39494 & 0.00173 \\
\hline & 14 & 0.38205 & 0.00175 \\
\hline & 15 & 0.37174 & 0.00177 \\
\hline & 16 & 0.36351 & 0.00178 \\
\hline & 17 & 0.35693 & 0.00179 \\
\hline & 18 & 0.35168 & 0.00180 \\
\hline & 19 & 0.34748 & 0.00180 \\
\hline & 20 & 0.34412 & 0.00181 \\
\hline \multirow{20}{*}{ ASE } & 1 & -29.12128 & 0.67841 \\
\hline & 2 & -6.08465 & 0.70736 \\
\hline & 3 & 11.25151 & 0.65837 \\
\hline & 4 & 28.30599 & 0.63764 \\
\hline & 5 & 41.92434 & 0.61643 \\
\hline & 6 & 53.02835 & 0.60067 \\
\hline & 7 & 61.90455 & 0.58779 \\
\hline & 8 & 69.01228 & 0.57757 \\
\hline & 9 & 74.69200 & 0.56938 \\
\hline & 10 & 79.23123 & 0.56284 \\
\hline & 11 & 82.85816 & 0.55762 \\
\hline & 12 & 85.75617 & 0.55345 \\
\hline & 13 & 88.07170 & 0.55011 \\
\hline & 14 & 89.92183 & 0.54745 \\
\hline & 15 & 91.40009 & 0.54532 \\
\hline & 16 & 92.58123 & 0.54362 \\
\hline & 17 & 93.52496 & 0.54226 \\
\hline & 18 & 94.27901 & 0.54117 \\
\hline & 19 & 94.88150 & 0.54031 \\
\hline & 20 & 95.36290 & 0.53900 \\
\hline
\end{tabular}

Table 15. Variance decomposition by variable

\begin{tabular}{cccc}
\hline Variable & Lead & PEX & ASE \\
\hline & 1 & 1.00000 & 0.00000 \\
& 2 & 0.98267 & 0.01733 \\
PEX & 3 & 0.96232 & 0.03768 \\
& 4 & 0.93577 & 0.25861 \\
& 10 & 0.74139 & 0.47615 \\
\hline \multirow{2}{*}{ ASE } & 20 & 0.52385 & 0.99897 \\
& 1 & 0.00103 & 0.99776 \\
& 2 & 0.00224 & 0.99830 \\
& 3 & 0.00170 & 0.99765 \\
\end{tabular}




\section{Conclusion}

It is worthwhile to note that the study has proven that the two stock market indexes in Palestine and Jordon are cointegrated statistically. From the Granger Causality test, the results indicate an absence of significant short-term dynamic between the two variables under study. On contrary, analysis of dynamic interactions during post-sample period (refer Table 14 and Table 15) suggests that PEX is the most endogenous of all. This supports our initial theory that performance of PEX depends upon the movements in ASE. One cannot dismiss the importance of a stock exchange as a leading economic indicator for the economy, particularly in the rejuvenating economic growth. Having known the equilibrium relationship between PEX and ASE, stock traders and value investors should be able to come out with a trading strategy that can protect the value of their investment portfolio. CUSUM analysis in depicted in Chart 2 suggests that both short-run and long-run parameters are stable over the study period.

It is now clear that neighboring countries, particularly Jordan, play some vital roles in supporting the local economy of Palestine. The evidence presented in this study clearly indicates the mutual benefits from international trade involving the two countries. Any economic progress in Jordan will undoubtedly flourish the Palestine economy as the two are sharing same border, same resources, same market structure, language and culture. Even though Jordan's constitution is based on constitutional monarch, the economic systems in the two countries are mostly based on market economy with some degree of government intervention. As such, regional economic cooperation should be explored between Palestine and Jordon in order to boast bilateral trade in the long run.

Overall, the financial model developed from this study can be regarded as compelling because there is no major setback in the diagnostic analysis. Besides, the empirical results are found to be consistent with earlier studies. Empirical evidence from the past indicates that the regional stock market performances are mostly inter-connected. Perhaps future study should look into incorporating more samples by considering other neighboring countries in the region like Egypt and Israel. Palestine government must relook at their foreign policy and focuses on beefing up bilateral trades among its neighboring countries. The fact that business globalization is inevitable; some new measures must be introduced before they get too late. The economic prosperity of Palestine does depend on its future foreign and trade policies in the Middle East.

\section{References}

Abdel, K., \& Ijbara. (2010). Evidence on Corporate Governance Compliance by Palestine Securities Exchange Listed Firms. Global Journal of Business Research, 4(3), 73-88.

Ahmed, S., \& Satter, Z. (2004). Impact of Trade Liberalisation Looking at the Evidence. Economics and Political Weekly, 12.

Bank for International Settlements. (2009). Global Capital Market. BIS Quarterly Review.

Baysan, T. (1999). Bangladesh Trade Liberalization Its Pace and Impacts. Poverty Reduction and Economic Management Unit. South Asia Region, Report No. 19591- BD.

Benjamin, M., \& Eduardo, J. (2002). Causality and Cointegration in stock Markets: The Case of Latin America. Journal of Finance, 5, 1-28.

Claude, L. (2006). A panel Unit Root Test with Good Power in Small Samples. New York: University of Cincinnati Publication.

Dicken, P. (1992). Global Shift: The Internationalization of Economic Activity. London: Guilford Press.

Dollar, D. (1992). Outward-Oriented Developing Countries Really Do Grow More Rapidly: Evidence from 95 LDCs, 1976-85. Economic Development and Cultural Change, 523-544. http://dx.doi.org/10.1086/451959

Domowitz, I., Glen, J., \& Madhavan, A. (1997). Market Segmentation and Stock Prices: Evidence from an $\begin{array}{lllll}\text { Emerging } & \text { Market. Journal }\end{array}$ http://dx.doi.org/10.1111/j.1540-6261.1997.tb02725.x

Duffy, D., \& Murry, L. (1994). The Wooing of American Investors. The Wall Street Journal.

Engle, R., \& Granger, C. (1987). Co integration and Error Correction Representation: Estimation and Testing. Econometrica, 55, 251-276. http://dx.doi.org/10.2307/1913236

Frankel, J., \& David, R. (1996). Trade and Growth: An Empirical Investigation. NBER Working Paper Series No. 5476 .

Granger, C. W. J. (1986). Development in the study of cointegrated variables. Oxford Bulletin of Economics and 
Statistics, 48, 213-228. http://dx.doi.org/10.1111/j.1468-0084.1986.mp48003002.x

Granger, C. W. J., \& Weiss, A. (1981). Some properties of time series data and their use in economic model specification. Journal of Econometrics, 16(a), 121-130. http://dx.doi.org/10.1016/0304-4076(81)90079-8

Granger, C. W. J., \& Weiss, A. (1983). Economics, Time Series and Multivariate Statistics. New York: Academic Press.

Hadi, A. R., Yahya, M. H., \& Shaari, A. H. (2009). The Effect of Oil Price Fluctuations on the Malaysian and Indonesian Stock Markets. Asian Journal of Business and Accounting, 2(1\&2), 69-91.

Heckscher, E. (1919). The Effects of Foreign Trade on the Distribution of Income. Economisk Tidskrift, 21, 497-512.

Imran, A., Kashif, U., Ayse, K., Muhammad, A., \& Hasan, A. (2010). Causal relationship between macro-economic indicators and stock exchange prices in Pakistan. African Journal of Business Management, 4(3), 312-319.

Kamal, A. (2005). Stock Market Growth: An Analysis of Cointegration and Causality. Economic Issues, 10(1), 25-34.

Lairellakpam, Govind, \& Dash, M. (2012). A Study of Granger Causality of Macroeconomic Factors on Indian Stock Markets. http://dx.doi.org/10.2139/ssrn.1988811

Mine, A., Faruk, A., \& Nuriye, Z. (2011). Cointegration of MENA Stock Markets: Turkey, Egypt and Israel. International Research Journal of Finance and Economics, 76(10), 47-66.

Murad, H., \& Haneen. (2010). Testing for correlational and causality relationships between stock prices and macroeconomic variables the case of Palestine Securities Exchange. Working Paper, Department of Finance Birzeit University.

Ohlin, B. (1933). Interregional and International Trade. Cambridge, Mass: Harvard Press.

Palestinian National Authority. (2011). Building Palestine, achievements and challenges. Special Report.

Pilinkus, D. (2009). Stock Markets and macroeconomic variables: evidences from Lithuania. Journal of Economics and Management, 14, 45-53.

Ricardo, D. (1817). Principles of Political Economy and Taxation. London: Murray Publication.

Richard, F. U. (2012). On the Cointegration of International Stock indices. Economic Finance, 36, 463-480. http://dx.doi.org/10.1007/s12197-010-9136-9

Said, E., Mahmoud, A., \& Hanin, S. (2008). Globalization and Investment Opportunities: A Cointegration Study of Arab, U.S., and Emerging Stock Market. The Financial Review, 43, 591-611. http://dx.doi.org/10.1111/j.1540-6288.2008.00204.x

Smith, A. (1776). The Wealth of Nations. London: Strahan Cadell Publication.

The Palestine Economic Policy Research Institute. (2010). Overview of the Palestinian Economy. Special Report, 3, 10-12.

Wacziarg, R. (1998). Measuring the Dynamic Gains from Trade. Policy Research Working Paper No. 2001. Retrieved from http://wber.oxfordjournals.org/content/15/3/393.short

World Bank. (2003). Twenty-Seven Months-Intifada, Closures and Palestinian Economic Crisis: An Assessment. Special Report to the Ad Hoc Liaison Committee.

World Bank. (2011). Sustaining Achievements in Palestinian Institution-Building and Economic Growth. Economic Monitoring Report to the Ad Hoc Liaison Committee. 